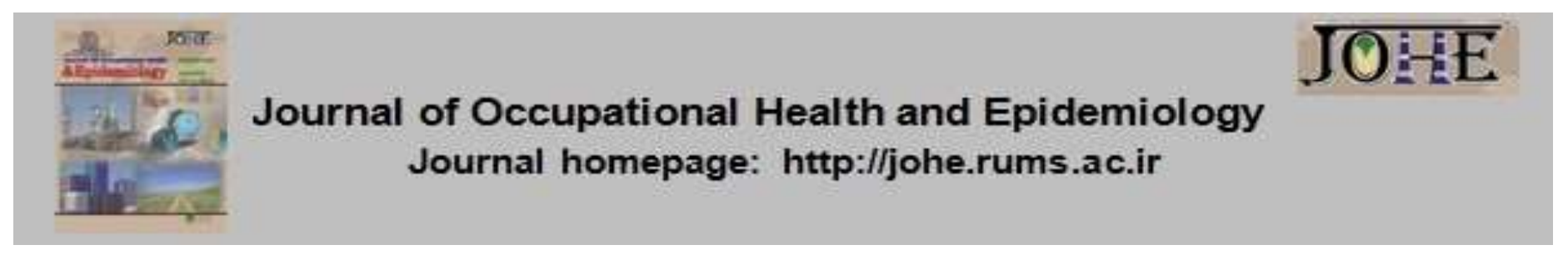

\title{
A study of people who attempted suicide referred to the emergency ward of Ali Ibn Abi Taleb hospital, Rafsanjan, Iran (2016)
}

\author{
Alireza Taherifard ${ }^{1}$, Hassan Ahmadinia ${ }^{2}$, Reza Vazirinejad ${ }^{3}$, Zahra Javadi ${ }^{4}$, Seyed Zia Tabatabaei ${ }^{5}$, \\ Mohsen Rezaeian $6^{*}$ \\ 1- MSc, Occupational Environment Research Center, Rafsanjan University of Medical Sciences, Rafsanjan, Iran. \\ 2- PhD Student in Biostatistics, Occupational Environment Research Center, Rafsanjan University of Medical Sciences, Rafsanjan, \\ Iran. \\ 3- Professor in Epidemiology, Social Determinants of Health Research Center, Rafsanjan University of Medical Sciences, Rafsanjan, \\ Iran. \\ 4- MSc in Mental Health, Rafsanjan University of Medical Sciences, Rafsanjan, Iran. \\ 5- Assistant Prof., Occupational Environment Research Center, Rafsanjan University of Medical Sciences, Rafsanjan, Iran. \\ 6- Professor in Epidemiology, Occupational Environment Research Center, Rafsanjan University of Medical Sciences, Rafsanjan, \\ Iran.
}

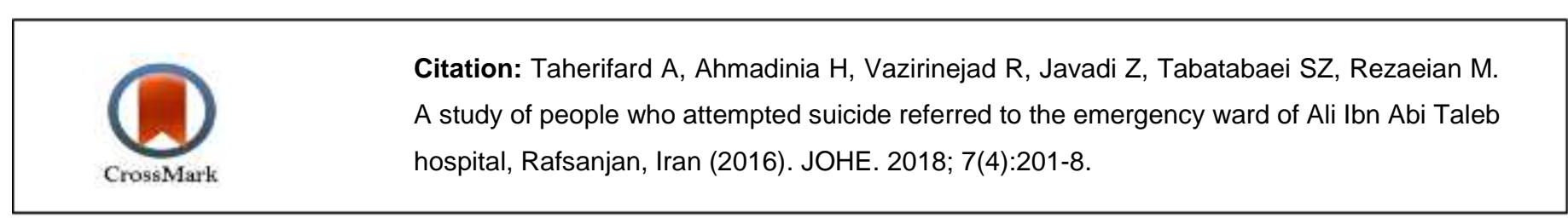

Article Info

* Corresponding author:

Mohsen Rezaeian,

E-mail:

moeygmr2@yahoo.co.uk

\section{Article history}

Received: Jun, 2018

Accepted: Dec, 2018

10.29252/johe.7.4.201

Print ISSN: 2251-8096 Online ISSN: 2252-0902

Peer review under responsibility of Journal of Occupational Health and Epidemiology

\section{Abstract}

Background: Suicide attempts, being considered from among psychiatric emergencies, are under the category of social and health problems that affect the individual, the family, and even the community. This study was conducted to determine the characteristics of people who attempted suicide referred to the emergency ward of Ali Ibn Abi Taleb hospital in the city of Rafsanjan, Iran in 2016.

Materials and Methods: This descriptive study was conducted using a census on 347 individuals who had attempted to suicide and were referred to the emergency ward of Ali Ibn Abi Taleb hospital in the city of Rafsanjan, in 2016. Data collection was conducted on a monthly basis using the checklist of the suicide prevention plan provided to the emergency wards by the health department. The data were analyzed using SPSS and Chi-square and Fisher's exact tests were applied.

Results: 347 cases of suicide attempts were occurred, with three cases $(0.9 \%)$ leading to death. The mean age of the individuals who attempted suicide was 26.15 years, with the standard deviation of 8.81 years. Among those individuals, 268 individuals (77.2\%) had attempted suicide only once, 54 individuals (13\%) twice. About 190 individuals (54.8\%) were women, and 138 individuals (73.4\%) carried out suicide using drugs.

Conclusion: It can be concluded that considering the easy access of the people to drugs, the most prevalent method of suicide was using drugs. Besides, having the highest percentage of suicide, women are leading in suicide attempts.

Keywords: Suicide Attempted, Epidemiology, Suicide, Iran.

\section{Introduction}

Suicide could be defined as the intentional act of self-harm that causes death. In contrast, a suicide attempt is not an intentional act of self-harm with the purpose of seeking death, but it is an act by which the person intends to attract the attention of others to himself to bring about a behavioral change (1).
Suicide attempts are under the category of social and health problems that affect the individual, the family, and even the community, in the occurrence of which various geographical, environmental, cultural, economic, and social factors are influential (2-4). According to the WHO report of 2014, approximately 800000 people died by suicide and 
20 times this number attempted suicide in 2012. In addition, according to the report of the mentioned organization, $75.5 \%$ of suicides in the world occur in the low-income and middle-income countries (5). Psychologists have shown in many studies that factors effective in suicide attempts vary in different countries (6). According to a WHO report, suicide attempts lead to a significant social and economic burden. The reason is that those who have a record of suicide attempts are more at the risk of death, so identifying such high-risk individuals and offering healthcare services can be a key factor in creating plans for the prevention of suicide (5).

Studies show that the rate varies in different countries. In other words, the highest rate is related to the Scandinavian countries, Germany, Eastern Europe, Australia, and Japan with 25/100000 individuals per year, and the lowest rate is for the countries of Spain, Italy, Ireland, the Netherlands, and Egypt, with 10/100000 individuals per year. Suicide rates are low in Muslim countries in such a way that in Kuwait, the rate has been reported at $0.1 / 100000$ individuals, and in Pakistan it has been reported less than $5 / 100000$ of the population (7).

Based on the Iranian Labour News Agency (ILNA) between the years 2001 and 2012, 41079 individuals (men and women) carried out suicide in Iran (8). Although the rates of suicide and suicide attempts in Iran are lower than the most of Western countries, they are higher than those of the rest of the Middle East countries (9). Iran's global rank is $58^{\text {th }}$ in this regard, with the suicide rate being quite different inside the country (10-12). Therefore, suicide attempts can be regarded as multi-faceted phenomena affected by various personal and environmental factors, such as age, sex, marital status, time, location, etc. According to the studies carried out in Iran, the most prevalent suicide methods used by men have been hanging and firearms, with self-immolation having been the most prevalent case for women (13).

According to the studies done in the city of Rafsanjan in 2006 on suicide attempts, $53.2 \%$ of 269 suicide attempters were men, and the rest were women, with the most prevalent method having been drug poisoning by $78.4 \%$ (14). Based on the discussions above, the present study was conducted to determine the characteristics of people who attempted suicide referred to the emergency ward of Ali Ibn Abi Taleb hospital in the city of Rafsanjan, in 2016, to create a real image of the status quo to plan for appropriate health interventions.

\section{Materials and Methods}

This cross-sectional study was conducted using a census on 347 individuals who had attempted suicide and referred to the emergency ward of Ali Ibn Abi Taleb hospital in the city of Rafsanjan, in 2016. This research was implemented after approval by the research council of the Center for Occupational Environment Research, the confirmation of the Research Department, and the agreement of the Ethics Committee under the code IR.RUMS.REC.1396.178.

With a population of 273902 , this city is covered by Rafsanjan University of Medical Sciences. The university has three public hospitals, with its largest hospital being Ali Ibn Abi Taleb hospital with more than 300 beds. Based on the decisions made by the medical emergency department and the emergency ward of this hospital, all the cases of suicide attempts within Rafsanjan refer to this emergency ward.

Data collection is reported on a monthly basis using the checklist for the suicide prevention plan provided to the emergency ward by the mental health division of the health department. The information of this checklist has two general sections, in the first section demographic information, such as age, gender, marital status, education, and occupation, and in the second part other information about suicide and suicide attempts, including the record of suicide attempts as well as the method and outcome of suicide are registered.

The data collected were entered into SPSS version 21 and analyzed. The descriptive results were reported in numbers and percentages, and for the statistical analysis, the ratio comparison method, the Chi-square test, and the independent t-test were used, with the level of significance considered at $5 \%$ for all tests.

\section{Results}

The findings of the present study indicated that in the city of Rafsanjan in 2016, 347 individuals attempted suicide. Considering the population of that city in the mentioned year (273902 individuals), the prevalence rate of suicide attempts was $127 / 100000$ individuals, with this rate having been $112 / 100000$ individuals in men and 142/100000 individuals in women.

The mean age of the individuals who attempted suicide was 26.15 years with the standard deviation of 8.81 years. The mean age in the men and women who attempted suicide was compared using the independent T-test. Based on the results of this test, the mean age of the women was 24.25 years with 
the standard deviation of 8.00 , and the mean age of the men was 27.19 years with the standard deviation of 9.63 , with the difference being statistically significant $(p=0.018)$.

From those who had attempted suicide, three individuals (equaling $0.9 \%$ ) died. From the perspective of the record of suicide attempts, the frequency of 268 individuals $(77.2 \%$ ) had attempted suicide only once. The majority of the cases of attempted suicides were related to married people with a frequency of 201 married individuals (57.9\%), where 190 individuals (54.8\%) who attempted suicide in 2016 in the city of Rafsanjan were women and 157 individuals (45.2\%) were men. The most prevalent method of suicide was the use of drugs in most people with the frequency of 226 individuals (65.1\%). Regarding their education, 114 individuals (32.9\%) out of those who attempted suicide had secondary school education (Table 1 ).

Table1: The frequency distribution of demographic features of suicide attempts in the city of Rafsanjan in 2016

\begin{tabular}{|c|c|c|c|}
\hline Variables & & Frequency & Percentage \\
\hline \multirow{2}{*}{ Sex } & Male & 157 & 45.2 \\
\hline & Female & 190 & 54.8 \\
\hline \multirow{3}{*}{ Marital status } & Single & 135 & 38.9 \\
\hline & Married & 201 & 57.9 \\
\hline & Divorced & 11 & 3.2 \\
\hline \multirow{5}{*}{ Education level } & Elementary school and lower & 56 & 16.1 \\
\hline & Middle school & 95 & 27.4 \\
\hline & Secondary school & 114 & 32.9 \\
\hline & Higher education & 53 & 15.3 \\
\hline & Unknown & 29 & 8.4 \\
\hline \multirow{6}{*}{ Suicide attempt method } & Medications & 226 & 65.1 \\
\hline & Poisons & 53 & 15.3 \\
\hline & Narcotics & 47 & 13.5 \\
\hline & Self-immolation & 3 & .9 \\
\hline & Cold weapons & 1 & .3 \\
\hline & Others & 17 & 4.9 \\
\hline \multirow{4}{*}{ Number of suicide attempt cases } & 1 & 268 & 77.2 \\
\hline & 2 & 45 & 13.0 \\
\hline & 3 & 19 & 5.5 \\
\hline & 4 or more & 15 & 4.3 \\
\hline \multirow{3}{*}{ Suicide attempt outcome } & Survived & 344 & 99.1 \\
\hline & Died & 3 & 0.9 \\
\hline & Total & 347 & 100 \\
\hline
\end{tabular}

The marital status of those who attempted suicide was compared in the two groups of women and men, making use of the Chi-square test. In this respect, 125 women $(65.8 \%)$ who attempted suicide were married, with the number for the married men being 76 individuals (48.4\%). Likewise, 78 individuals $(49.7 \%)$ of the men who attempted suicide were single, with the number reported for the single women being 57 individuals (30\%). Based on the Chi-square test, the ratio of the individuals was not the same based on the marital status in the two groups of men and women $(p<0.001)$ (Table 2).

Table 2: The frequency distribution of marital status in suicide attempters in the city of Rafsanjan, in 2016

\begin{tabular}{|c|c|c|c|c|c|}
\hline \multirow{2}{*}{ Marital status } & \multicolumn{2}{|c|}{ Female } & \multicolumn{2}{|c|}{ Male } & \multirow{2}{*}{ Chi-square Test } \\
\hline & Number & Percentage & Number & Percentage & \\
\hline Single & 57 & 30.0 & 78 & 49.7 & \\
\hline Married & 125 & 65.8 & 76 & 48.4 & Df -2 \\
\hline Divorced & 8 & 4.2 & 3 & 1.9 & $\begin{array}{l}\mathrm{D} t=2 \\
\mathrm{P}<0 \Omega 01\end{array}$ \\
\hline Total & 190 & 100.0 & 157 & 100.0 & \\
\hline
\end{tabular}

Making use of the Fischer's exact test, the frequency and percentage of various methods of suicide attempts were compared in the two groups of men and women. The results demonstrated that 138 individuals $(72.6 \%)$ of the women who attempted suicide used drugs, while the number was 88 individuals $(56.1 \%)$ in the men who attempted suicide. Based on the results of this test, the ratio of the individuals who used various methods of attempting suicide was not the same in the two groups of men and women. The reason is that the frequency distribution of suicide methods 
was different in the two groups of men and women. For instance, the use of drugs was more in women than men, and the use of narcotics was more in men than women $(p=0.005)$ (Table 3$)$.

Table 3: The frequency distribution of various methods of suicide attempts, by gender, in the city of Rafsanjan, in 2016

\begin{tabular}{|c|c|c|c|c|c|}
\hline \multirow{2}{*}{ Suicide method } & \multicolumn{2}{|c|}{ Female } & \multicolumn{2}{|c|}{ Male } & \multirow{2}{*}{ Fisher's exact test } \\
\hline & Number & Percentage & Number & Percentage & \\
\hline Medications & 138 & 72.6 & 88 & 56.1 & \multirow{7}{*}{$\begin{array}{l}X^{2}=14 / 69 \\
D f=5 \\
P=0.005\end{array}$} \\
\hline Poisons & 27 & 14.2 & 26 & 16.6 & \\
\hline Narcotics & 16 & 8.4 & 31 & 19.7 & \\
\hline Self-immolation & 2 & 1.1 & 1 & 0.6 & \\
\hline Cold weapon & 0 & 0 & 1 & 0.6 & \\
\hline Others & 7 & 3.7 & 10 & 6.4 & \\
\hline Total & 190 & 100.0 & 157 & 100.0 & \\
\hline
\end{tabular}

In this study, the frequency distribution of different methods of suicide attempts was compared in the three groups of single, married, and divorced where about $83(61.5 \%)$ single and $135(62.7 \%)$ of married individuals used drugs. According to the Fisher's exact test, although the ratios of the individuals using different methods of suicide attempts were different, they were not statistically significant $(p=0.276)$ (Table 4).

Table 4: The frequency distribution of various methods of suicide attempts, by marital status, in the city of Rafsanjan, in 2016

\begin{tabular}{lccccccc}
\hline \multirow{2}{*}{ Suicide attempt method } & \multicolumn{2}{c}{ Single } & \multicolumn{2}{c}{ Married } & \multicolumn{2}{c}{ Divorced } & Fisher's \\
\cline { 2 - 7 } & Number & Percentage & Number & Percentage & Number & Percentage & exact test \\
\hline Medications & 83 & 61.5 & 135 & 67.2 & 8 & 72.7 \\
\hline Poisons & 24 & 17.8 & 26 & 12.9 & 3 & 27.3 & \\
\hline Narcotics & 16 & 11.9 & 31 & 15.4 & 0 & 0 & $X^{2}=12.27$ \\
\hline Self-immolation & 1 & 0.7 & 2 & 1.0 & 0 & 0 & Df $=10$ \\
\hline Cold weapon & 0 & 0 & 1 & 0.5 & 0 & 0 & P $=0.276$ \\
\hline Others & 11 & 8.1 & 6 & 3.0 & 0 & 0 & \\
\hline Total & 135 & 100.0 & 201 & 100.0 & 11 & 100.0 \\
\hline
\end{tabular}

In this study, $66(57.9 \%)$ of those who suicide attempts medication had secondary school education whilst 42(79.2\%) had higher education. The comparison results of various suicide attempts in different groups in terms of education and test results demonstrated that although the ratios of the individuals who used different methods of suicide attempts differed, they were not statistically significant $(p=0.253)$ (Table 5).

Table 5: The frequency distribution of various methods of suicide attempts, by the education level, in the city of Rafsanjan, in 2016

\begin{tabular}{|c|c|c|c|c|c|c|c|c|c|c|c|}
\hline \multirow[b]{2}{*}{$\begin{array}{l}\text { Suicide } \\
\text { attempt } \\
\text { method }\end{array}$} & \multicolumn{2}{|c|}{$\begin{array}{c}\text { Elementary } \\
\text { school and less }\end{array}$} & \multicolumn{2}{|c|}{$\begin{array}{l}\text { Middle } \\
\text { school }\end{array}$} & \multicolumn{2}{|c|}{$\begin{array}{c}\text { Secondary } \\
\text { school }\end{array}$} & \multicolumn{2}{|c|}{$\begin{array}{c}\text { Higher } \\
\text { education }\end{array}$} & \multicolumn{2}{|c|}{ Others } & \multirow[b]{2}{*}{$\begin{array}{c}\text { Fisher's } \\
\text { exact test }\end{array}$} \\
\hline & $\frac{\text { ¿̀ }}{\frac{0}{\varepsilon}}$ & 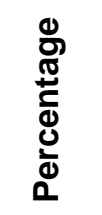 & 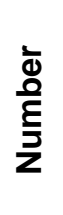 & 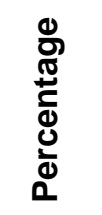 & $\frac{\grave{D}}{\frac{0}{E}}$ & 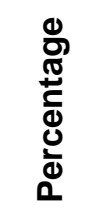 & $\frac{\grave{\Phi}}{\frac{0}{E}}$ & 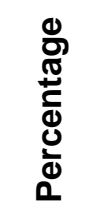 & 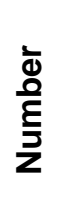 & 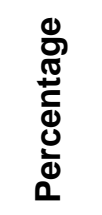 & \\
\hline Medications & 35 & 62.5 & 60 & 63.2 & 66 & 57.9 & 42 & 79.2 & 23 & 79.3 & \multirow{7}{*}{$\begin{array}{l}X^{2} \\
=21.79 \\
D f=20 \\
P=0.253\end{array}$} \\
\hline Poisons & 10 & 17.9 & 13 & 13.7 & 23 & 20.2 & 3 & 5.7 & 4 & 13.8 & \\
\hline Narcotics & 7 & 12.5 & 12 & 12.6 & 20 & 17.5 & 7 & 13.2 & 1 & 3.4 & \\
\hline Self-immolation & 1 & 1.8 & 2 & 2.1 & 0 & 0 & 0 & 0 & 0 & 0 & \\
\hline Cold weapon & 0 & 0 & 1 & 1.1 & 0 & 0 & 0 & 0 & 0 & 0 & \\
\hline Others & 3 & 5.4 & 7 & 7.4 & 5 & 4.4 & 1 & 1.9 & 1 & 3.4 & \\
\hline Total & 56 & 100.0 & 95 & 100.0 & 114 & 100.0 & 53 & 100.0 & 29 & 100.0 & \\
\hline
\end{tabular}


Using the Chi-square test, the frequency distribution of the number of suicide attempts in the two groups of women and men was compared. Approximately $66 \%$ of the women and $91 \%$ of the in this study attempted suicide only once, and the rest more than once. Based on the results of this test, the ratio of the number of attempted suicides was not the same in the two groups of men and women $(p<0.001)$.

Besides, the frequency and percentage of the number of suicide attempts were compared in the groups of single, divorced, and married women. The results showed that $78.8 \%$ of the single and divorced individuals attempted suicide only once, while the number was reported to be $76 \%$ in married individuals. Considering the Chi-square test results, the ratio of the number of suicide attempts was the same in the two groups, with the negligible difference being statistically insignificant $(p=0.607)$ (Table 6)

Table 6: The distribution frequency of the number of suicide attempts, by gender, and marital status in the city of Rafsanjan, in 2016

\begin{tabular}{|c|c|c|c|c|c|c|c|c|c|c|}
\hline \multirow[b]{3}{*}{ Variable } & \multirow[b]{3}{*}{$\begin{array}{c}\text { Variable } \\
\text { levels }\end{array}$} & \multicolumn{8}{|c|}{ Number of attempted suicides } & \multirow[b]{3}{*}{$\begin{array}{c}\text { Chi-square } \\
\text { test }\end{array}$} \\
\hline & & \multicolumn{2}{|c|}{ One } & \multicolumn{2}{|c|}{ Two } & \multicolumn{2}{|c|}{ Three } & \multicolumn{2}{|c|}{$\begin{array}{c}\text { Four or } \\
\text { more }\end{array}$} & \\
\hline & & 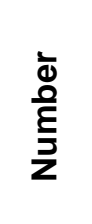 & 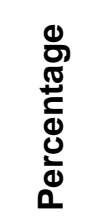 & $\begin{array}{l}\frac{1}{ \pm} \\
\text { है } \\
\text { క̇ }\end{array}$ & 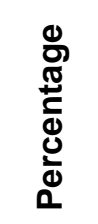 & $\begin{array}{l}\frac{1}{\Phi} \\
\frac{0}{E} \\
\frac{\Sigma}{Z}\end{array}$ & 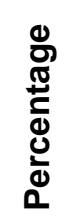 & $\begin{array}{l}\frac{1}{ \pm} \\
\frac{0}{E} \\
\bar{z}\end{array}$ & 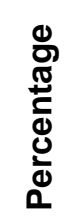 & \\
\hline \multirow{2}{*}{ Sex } & Male & 143 & 91.1 & 10 & 6.4 & 2 & 1.3 & 2 & 1.3 & \multirow{2}{*}{$\begin{array}{l}X^{2}=32.16 \\
D F=3 \\
P<0.001\end{array}$} \\
\hline & Female & 125 & 65.8 & 35 & 18.4 & 17 & 8.9 & 13 & 6.8 & \\
\hline \multirow{2}{*}{$\begin{array}{l}\text { Marital } \\
\text { status }\end{array}$} & $\begin{array}{l}\text { Single and } \\
\text { divorced }\end{array}$ & 115 & 78.8 & 18 & 12.3 & 9 & 6.2 & 4 & 2.7 & \multirow{2}{*}{$\begin{array}{l}X^{2}=1.83 \\
D F=3 \\
P=0.607\end{array}$} \\
\hline & Married & 153 & 76.1 & 27 & 13.4 & 10 & 5.0 & 11 & 5.5 & \\
\hline
\end{tabular}

\section{Discussion}

Considering the results of the present study, the number of suicide attempts in the city of Rafsanjan has been 347 in 2016 with the rate of $127 / 100000$ of the population, including 112 men and 142 women per a hundred thousand individuals. The results of a study within the time period of 2005 to 2007 in the Markazi Province demonstrated that the rate of suicide attempts was $173.2 / 100000$ of the population, including 111.83 men and 163.53 women per a hundred thousand individuals (15). The results of a study in the city of Jiroft in 2001 demonstrated that the rate of suicide attempts was $200 / 100000$ of the population (16).

In this study, the mean age of the individuals who attempted suicide was 26.15 years with the standard deviation of 8.81 years, being 24.95 and 27.19 years old in women and men, respectively. In a similar study conducted in the province of Qazvin within the time period of 2013 to 2016 , the mean age of the individuals who attempted suicide was reported to be 44 . $26 \pm 77.91$ (17). In a study by Shokrzadeh in the province of Gorgan within the time period of 2008 to 2014 on suicide attempters by poisoning, their mean age was estimated to be $24.54 \pm 8.14$ years (18). In a similar study in the province of Chahar Mahal va Bakhtiari within the time period of 2003 to 2012 on suicide attempters, their mean age was estimated to be $25.25 \pm 65.95$ years (19).

This study showed that $0.9 \%$ of suicide attempt cases resulted in death. In a study conducted in the cities of Lar and Grash, it was reported that from 792 cases of suicide attempts within the time period of 2008 to 2012,31 individuals (3.9\%) had lost their lives (13). In a similar study conducted in the province of llam within the time period of 2011 to 2014 , it was reported that out of 6818 cases of suicide attempts, $8.4 \%$ of them had lost their lives (20).

As WHO has reported that the suicide rate is higher in women than men (21), the present study showed that the suicide attempt rate was higher in women than men, with the frequency of (54.8\%) individuals. The studies on suicide attempts within the country have also shown that suicide attempt rates have been more in women than men, namely in the city of Kashan within the time period of 2003 to 2008 with the frequency of $59.7 \%$ in women (22), in the city of Dashtestan in 2004 with the frequency of $71.15 \%(23)$ in women, and in the city of Sabzvar in 2010 with the frequency of $61.2 \%$ in women (2). Therefore, it is required that suicide patterns in different groups be considered in order to decrease suicide attempts in such groups by utilizing efficient methods (24). 
Most studies on suicide attempts show that single individuals attempt suicide more than married individuals. Such studies have been conducted in the Province of Fars with the frequency of $59.3 \%$ (25), in the Province of Tehran with the frequency of $64.8 \%(26)$, and in the city of Rafsanjan with the frequency of $60.8 \%$ (14), all related to single individuals. However, in the current study, the highest frequency was seen in married individuals with the frequency of $57.9 \%$, with the married women showing the frequency of 125 individuals (65.8\%). This observation indicates a pattern change in the city of Rafsanjan over the last decade, implying that cultural factors and lifestyle changes have been effective in lowering married individuals' tolerance threshold.

In this study, the most common method of suicide attempts was drug poisoning with the frequency of $65.1 \%$ in both genders, but the ratio of the individuals using various methods of suicide attempts was not the same in the two sex groups. The first method selected, i.e. drug poisoning, was observed with the frequency of $72.6 \%$ and $51.6 \%$, in women and men, respectively. In a study conducted in the province of Khorasan Razavi within the time period of 2014 to 2015, the most common method of suicide attempts was reported to be drug poisoning with the frequency of $81.3 \%$ (3). In another study in the cities of Lar and Garash, within the time period of 1999 to 2012, the most common method of suicide attempts in women (93.4\%) and men (86.8\%) was reported to be drug poisoning (13). In another study conducted in the province of llam in 2005, the most common method of suicide attempts $(49.2 \%)$ was reported to be selfimmolation (27). In this study, drug poisoning ranked first in suicide attempts, the reason of which seems to have been the easy accessibility of drugs. Unlike this study, the education level of those who attempted suicide in the province of Markazi was higher than the secondary school diploma (15); however, in this study, the highest percentage of suicide attempts occurred among the individuals with the secondary school education with the frequency of $66.3 \%$. Similarly, according to the results of a study in the city of Rafsanjan in 2006 the highest education level of suicide attempters was the secondary school with the frequency of $44.7 \%$ (14). In other studies conducted in the city of Bandar Abbas in 2002 (28) and in the province of Hormozgan in 2014 (29), similar results were reported. In this study, the ratio of suicide attempters in different sex groups was the same in terms of the education level. Given the frequencies observed, it seems that higher education levels could be effective in empowering individuals and acquiring the skills required in facing life predicaments and crises.

In this study in which the records of suicide attempts were compared in the two groups of women and men, the results showed that approximately $65.8 \%$ and $34.2 \%$ of women attempted suicide only once and more than once, respectively. However, $8.9 \%$ of the men present in this study attempted suicide more than once. In a study conducted in the province of Golestan in 2012 , it was demonstrated that $6.7 \%$ of individuals had attempted suicide more than once (30). Various studies have demonstrated that from 10 to $40 \%$ of suicide attempts conducted more than once have led to death. One of the biggest problems among suicide attempters is the lack of a proper care program to prevent re-attempts $(31,32)$.

Given the limitations of the current research, including incompleteness of some information in the registration system, such as the address of suicide attempters and the causes of suicide, it is recommended that such information be registered more fully by upgrading the information registration system of suicide attempters.

\section{Conclusion}

In accordance with the findings of this study, it can be concluded that given the easy access to drugs by people, drug poisoning has the largest share of suicide attempts. Besides, women with the highest rate of suicide attempts in this study, are leading in suicide attempts, with the vulnerability of this class of the society in facing psychological and physical problems requiring more attention.

\section{Acknowledgement}

We would like to express our special thanks to the health staff for their collaboration in collecting the data required for this study.

Conflict of interest: None declared.

\section{References}

1. Rezaiean M. Suicide epidemiology. In: Hatami H, Razavi SM, Eftekharardabili $H$, Majlesi $F$, Seyednozadi M, Parizadeh SM, editors. Textbook of public health (Vol 3). $3^{\text {rd }}$ ed. Tehran: Arjmand Publication; 2004.

2. Nava Noorafshar Z, Kooshan M. Epidemiology of commit suicide in Sabzevar (2010-2011). Journal of Sabzevar University of Medical Sciences 2015; 22(3):220-4.

3. Khadem Rezaiyan M, Jarahi L, Moharreri F, Afshari R, Motamedalshariati SM, Okhravi N, et al. Epidemiology of suicide attempts in Khorasan 
Razavi province, 2014-2015. Iranian Journal of Epidemiology 2017; 13(2):128-35.

4. Daliri S, Bazyar J, Sayehmiri K, Delpisheh A, Sayehmiri F. The incidence rates of suicide attempts and successful suicides in seven climatic conditions in Iran from 2001 to 2014: a systematic review and meta-analysis. Scientific Journal of Kurdistan University of Medical Sciences 2017; 21(6):1-15.

5. World Health Organization. Preventing suicide: A global imperative, Mental health. Geneve: World Health Organization; 2014. Available from: https://www.who.int/mental_health/suicideprevention/world_report_2014/en/

6. Makinen $\mathrm{IH}$. Eastern Euopean transition and suicide mortality. Soc Sci Med 2000; 51(9):140520.

7. World Health Organization. Suicide data, Mental health. Geneve: World Health Organization; 2016. Available from:

https://www.who.int/mental_health/prevention/s uicide/suicideprevent/en/

8. Ahmadbeygi Sh, Khajenejad P. Latest statistics on suicide in Iran. Iranian Labour News Agency. [Internet]. 2016 Oct 23; Available from: http://www.ilna.ir.

9. Moradi SE, Khademi A. Evaluation of suicides resulting in death in Iran, comparing with the world rates. Scientific Journal of Forensic Medicine 2002; 8(27):16-21.

10. Mousavi F, Shahmohammadi D, Kaffashi A. Epidemiological survey of suicide in rural areas. Iranian Journal of Psychiatry \& Clinical Psychology 2000; 5(4):4-11.

11. Taziki $\mathrm{MH}$, Semnani $\mathrm{SH}$, Golalipour $\mathrm{M}$, Behnampour N, Taziki AS, Rajaee S, et al. Epidemiological survey of suicide in Golestan province in the North of Iran (2003). Journal of Mazandaran University of Medical Sciences 2006; 16(55):72-7.

12. Shamsi khani $S$, Rahgoo A, Falahi Khoshknab M, Rahgozar M. Effects of problem solving training on coping skills of suicidal clients. Iranian Journal of Nursing Research 2007; 1(3):31-9.

13. Gorgi Z, Sheikh Fathollahi M, Askarizadeh MK, Rezaeian M. Epidemiology of suicide and attempted suicide in the Larestan and Gerash during 2008 to 2012. Journal of Rafsanjan University of Medical Sciences 2014; 13(7):597608.

14. Ansari A, Khodadadi A, Sayadi AR, Negahban $\mathrm{T}$, Allahtavakoli M. Suicide attempts and related factors among referring to Ali Ebn-e Abitaleb hospital in Rafsanjan 2006-2007. Community Health 2006; 5(1):38-44.

15. Rafiei M, Seyfi A. The epidemiologic study of suicide attempt referred to hospitals of University of Medical Sciences in Markazi- province from 2002 to 2006. Iranian Journal of Epidemiology 2009; 4(3-4):59-69.
16. Zohoor AR, Aflatoonan MR. Epidemiological study of attempted suicide in Jiroft, Kerman (Autumn 2001). Razi Journal of Medical Sciences 2004; 10(38):913-9.

17. Yaghoubi Dost MH. Frequency of suicide attempt and its effective factors in Qazvin province. [Phd thesis]. Qazvin: University of Medical Sciences; 2017.

18. Shokrzadeh M, Hoseinpoor R, Hajimohammadi A, Delaram A, Shayeste Y. Epidemiological survey of suicide attempt by drug poisoning in Gorgan, Iran, 2008 to 2015. Journal of Mazandaran University of Medical Sciences 2016; 26(143):201-10.

19. Mobasheri M, Imani R, Alidousti M, Khosravi N. Epidemiologic study of suicide attempt cases in Chaharmahal and Bakhtiari province in 20032012. Journal of Clinical Research in Paramedical Sciences 2013; 1(4):e82312.

20. Veisani Y, Delpisheh A, Sayehmiri K, Moradi G, Hassanzadeh J. Suicide attempts in llam Province, Western Iran, 2010-2014: a time trend study. J Res Health Sci 2016; 16(2):64-7.

21. World Health Organization. Preventing Suicide: A global imperative. Geneve: World Health Organization; 2014. Available from: http://apps.who.int/iris/bitstream/handle/10665/1 31056/9789241564779_eng.pdf

22. Moravveji SA, Saberi H, Akasheh G, Ahmadvand A, Kiani-Pour S. Epidemiology of attempted suicide in Kashan during 2003-8. Feyz 2011; 15(4):374-81.

23. Ghaedi $H$, Mohammadi Baghmollaei M, Hashemi SM, Saniei F, Hosseini SY, Jabbarnejad A. Epidemiological study of suicide attempt in Dashtestan region in 2004. Dena 2006; 1(3):5360

24. Levi F, La Vecchial C, Saraceno B. Global suicide rates. Eur J Public Health 2003; 13(2):978.

25. Zarenezhad M, Gorgi Z, Sheikh Fathollahi M, Gholamzadeh S, Ghadipasha M, Rezaeian M. Epidemiological survey of suicide in Fars province in the south of Iran during 2003 to 2011. Journal of Rafsanjan University of Medical Sciences 2015; 13(12):1129-40.

26. Shaker SH, Hosseini Kasnaviyyeh SM, Basir Ghafouri H, Tavakkoli N, Yasinzadeh M, Masoumi Gh, et al. Epidemiological survey of the attempted suicide patients admitted at Hazrat Rasoul hospital in Tehran 2007-2011. Scientific Journal of Forensic Medicine 2017; 23(1):7-15.

27. Rezaeian M, Daneshkohan A, Sharifirad Gh, Jahani B, Bahmani R, Fathollahi E, et all. Suicide epidemiological pattern within llam province, Iran. Health system research 2012; 7(6):819-28.

28. Yousefi H, Sobhani GH, Asadinoghabi F. Suicide risk factors between those who committed suicide Bandar Abbas, Iran. Medical Journal of Hormozgan University 2002; 6(2):1320. 
29. Khajeh E, Hosseinpour M, Sedigh B, Rezvani Y. Image of suicide in Hormozgan province, 2012. Medical Journal of Hormozgan University 2013; 17(1):61-7.

30. Fleischmann A, Bertolote JM, Wasserman D, De Leo D, Bolhari J, Botega NJ, et al. Effectiveness of brief intervention and contact for suicide attempters: a randomized controlled trial in five countries. Bull World Health Organ 2008; 86(9):703-9.

31. Pavarin RM, Fioritti A, Fontana F, Marani S, Paparelli A, Boncompagni G. Emergency department admission and mortality rate for suicidal behavior: A follow-up study on attempted suicides referred to the ED between January 2004 and December 2010. Crisis 2014; 35(6):406-14 .

32. Cho J, Lee WJ, Moon KT, Suh M, Sohn J, Ha $\mathrm{KH}$, et al. Medical care utilization during 1 year prior to death in suicides motivated by physical illnesses. J Prev Med Public Health 2013; 46(3):147-54. 